\title{
The Impact of Meteorological Parameters on the Pattern of Malaria Incidence Rate in the Northwest, Ethiopia; Repeated Cross-sectional Study Design With Bayesian Approach
}

\author{
Asefa Adimasu ( $\sim$ adimasuasefa@gmail.com ) \\ University of Gondar College of Medicine and Health Sciences \\ Adhanom Gebreegziabher Baraki \\ University of Gondar College of Medicine and Health Sciences \\ Kassahun Alemu Gelaye \\ University of Gondar College of Medicine and Health Sciences \\ Dawit Wendimsigegn \\ University of Gondar College of Medicine and Health Sciences
}

\section{Research Article}

Keywords: Malaria incidence rate, Bayesian generalized negative binomial regression, meteorological parameters

Posted Date: May 24th, 2021

DOI: https://doi.org/10.21203/rs.3.rs-468969/v1

License: (c) (1) This work is licensed under a Creative Commons Attribution 4.0 International License. Read Full License 


\section{Abstract}

Background: Commonly the incidence of malaria was determined by some meteorological parameters. However, updated evidences were not reported in the study area and recently malaria is reported as an epidemic disease in Ethiopia particularly in Amhara regional state. Therefore the study was aimed to estimate malaria incidence proportion linked with some meteorological parameters.

Methods: A repeated cross-sectional study design was done in 8 districts of northwest Ethiopia. All malaria patients who visited the local health institutions in the study area were the study participants. A monthly malaria surveillance data were retrieved from 8 districts of North Gondar zone health department and metrological data were obtained from west Amhara metrology agency office monthly reported databases. Data was clean and analyzed by using R2 win bugs software. The bayesian generalized negative binomial regression model was fitted for parameter estimation.

Results: The overall average cumulative annual malaria incidence rate during the study period was 29.9 per 100 populations. In this study relative humidity (IRR; 1.04 (95\% BCl, 1.01-1.05), normalized difference vegetation index [IRR; $2.74(95 \%$ BCl, $1.35-$ 5.58)], altitude [IRR; 0.97(95\% BCl, 0.95 - 0.99], average maximum temperature [IRR; 1.07(95\% $\mathrm{BCl}(1.05$ - 1.09)] and average minimum temperature [IRR; 1.04 (95\% BCI (1.02-1.07)] were the statistically significant predictors. However, monthly rainfall, length of a sunshine hour, monthly wind speed was not associated with malaria incidence.

Conclusion: The research showed a greater incidence of malaria in the study area when compared to the national statistics. Climatic variability changes the pattern of the malaria incidence in the study area.

\section{Introduction}

Malaria is a mosquito-borne infectious human disease caused by the Plasmodium genus that is introduced by the bite of the infected female anopheles mosquito into the circulatory system(1). Parasites in the human body multiply in the liver, and infecting red blood cells. The situation in the poorest nations is one of the main public health challenges $(2,3)$.

The total amount of malaria cases has dropped from 262 million in 2000 to 214 million in 2015 worldwide. Ninety percent of malaria cases occur in Africa, however, the magnitude of the disease has reduced by 21\% from 2010 to 2015, However, in 2016, malaria has grown to 216 million globally, 81\% of which happen in sub-Saharan Africa, killing roughly 655,000 individuals annually(1). Of these total deaths, $91 \%$ occurred in sub-Saharan Africa, most of which are children under the age of 5-years. This is mainly due to P. falciparum, the most hazardous disease of the four human malaria parasites, which still generates a notable global burden, even though malaria-induced morbidity and mortality have decreased over the last century, in particular among females and kids under the age of five(3).

In Ethiopia, $75 \%$ of the country is malaria's with about $60 \%$ of the total population living in areas at risk of malaria. That is, there is a malaria danger of 50,6 million individuals, and malaria affects four to five million people every year $(1,3)$. The number of malaria cases was decreased from 2.8 million to 621345 in the last 25 years (4).

Amhara is one of Ethiopia's low land malaria regions. In 2011/2012, the incidence of malaria was $4.3 \%$ and the incidence rate was higher among men (4.8\%) than women (3.4\%) (5). P. falciparum and Plasmodium vivax are the dominant malaria species in the region. The region accounts for $31 \%$ (1.3 million cases) of Ethiopia's malaria burden(6).

In Ethiopia, malaria epidemiology is unique when compared to other African countries, both Plasmodium falciparum and Plasmodium vivax affecting the population and malaria transmission is generally unstable, with focal, seasonal outbreaks and occasional epidemics(7).

Statistical modeling offers a mathematical overview of relationships between environment and disease, identifies important environmental predictors of malaria transmission, and offers malaria risk projections based on the above relations with their accuracy. Independence from observations and variables is assumed by conventional statistical models. The occurrence of 
malaria is, however, clustering because of the clustering nature of conditions that favor its occurrence (8). Ignoring this spatial correlation and assuming independence causes overestimation of the statistical significance of the covariates(9).

Due to the growth of simulation techniques such as the $\mathrm{MCMC}(10)$, Bayesian statistic models have become potent techniques in modeling spatial data. These methods are used for the empirical re-distribution of parameters. The Gibbs sampler algorithm(11), Metropolis-Hasting algorithm(12), and the reversible Jump MCMC (12) are significant methodologies.

Understanding the connection between the incidence of malaria and environmental / climate variables is helpful to study how climate variability can influence long-term disease transmission and distribution(13).

In the latest years, there has been no study that considers both the lowland and highland areas. In this research, we used statistical modeling from the Bayesian point of view that offers a mathematical overview of relationships between environment and disease and identifies substantial environmental malaria transmission predictors along the way.

\section{Materials And Methods}

Study design and period: A repeated cross-sectional study was conducted using all malaria cases reported and all reported average monthly metrological data from eight districts in northwest Ethiopia 2016.

\section{Outcomes and predictors of the study}

The malaria incidence rate was the primary outcome variable and Average Monthly Maximum Temperature, Average Monthly Estimated Rainfall, Average Monthly Minimum Temperature, Average Monthly Elevation (Altitude), Average Sunshine Hour, Average Monthly Relative Humidity, and Normalized Difference Vegetation Index (NDVI) was the independent variables.

\section{Setting}

The study was performed in the northern part of Ethiopia in 2016. The area is one of the 11 zones of Amhara Regional State. According to the central statistics agency report, the total population of the study area is $38,004,589$ which covers $45,934.090$ square kilometers and the population density is 64 persons per square kilometer. Topographically the area contains two main parts, namely the lowlands (552 meters) and highlands (2926 meters) above sea level(14).

According to National oceanic and atmospheric service (NOAAS) classification, the study area had minimum (0.2) and maximum (0.6) normalized difference vegetation index (forest, shrub, grassland and vegetation's) $(15), 28.7^{\circ} \mathrm{C}$ and $14.1^{\circ} \mathrm{C}$ maximum and minimum temperatures respectively, 0 to $87.5 \%$ relative humidity and two rainy seasons: the main one from June to September, followed by a shorter one from March to May. The dry season ranges from October to February (16).

\section{Data Source}

Retrospectively, malaria data were acquired from monthly reports from the health department in northwest Ethiopia in 2016. The information was recorded in monthly surveillance forms from each district health center and subsequently reported to district health offices that are finally reported to the Zone health office. The malaria data sets were aggregated at the district level and it included data on total cases of malaria, parasite types (P. Falciparum, P. Vivax, and mixed infections), malaria cases of various age groups and times (month and year).

The climatic and environmental predictors used in this study were extracted from different web sources. Normalized difference vegetation index and Altitude were extracted from remote sensing data at $0.25 \mathrm{~km}$ by $0.25 \mathrm{~km}$ and $1 \mathrm{~km}$ by $1 \mathrm{~km}$ spatial resolution respectively from Moderate Resolution Imaging Spectro-radiometer (MODIS) (Fig. 1). The NDVI is a proxy measure of vegetation cover ranging from 1 to -1 . Positive values indicate the presence of vegetation and negative values and values close to zero represent barren or water surfaces. Elevation (distance above the sea level) data were extracted at $1 \mathrm{~km}$ resolution from Digital Elevation Model (DEM). MODIS and DEM are obtained from the U.S Geological Survey (USGS) EROS Data Center. Satellite-derived daily rainfall estimates were obtained from the Ethiopia Meteorology Agency (EMA) with $1 \mathrm{~km}$ 
by $1 \mathrm{~km}$ resolution. Monthly accumulated rainfalls $(\mathrm{mm})$ were summarized for each district from daily rainfall estimates (Table 1).

Table 1

The environmental data and the databases from which they were extracted

\begin{tabular}{|lll|}
\hline Factors & Resolution & Source \\
\hline $\begin{array}{l}\text { Normalized Difference Vegetation } \\
\text { Index (NDVI) }\end{array}$ & $2.5 \mathrm{~km}^{2}$ & $\begin{array}{l}\text { Moderate Resolution Imaging Spectro-radiometer (MODIS) } \\
\text { \{http://reverb.echo.nasa.gov/reverb\} }\end{array}$ \\
\hline $\begin{array}{l}\text { Maximum, Minimum, } \\
\text { Temperatures }\end{array}$ & - & $\begin{array}{l}\text { Ethiopia West Amhara meteorology agency (EWAMA) } \\
\text { Average Sunshine hour }\end{array}$ \\
\hline Estimated monthly Rainfall & - & Ethiopia West Amhara meteorology agency (EWAMA) \\
\hline Relative monthly humidity & - & Ethiopia West Amhara meteorology agency (EWAMA) \\
\hline Elevation (Altitude) & $1 \mathrm{~km}^{2}$ & Digital Elevation Model (DEM) \\
\hline
\end{tabular}

\section{Statistical Analysis}

All statistical analysis has been performed by $R$ software version 3.4.1 using packages like R2, MCTEST, ARM, CODA, MCMC, Bayes Boot and the Bayesian Tools.

Descriptive statistics such as proportion and the model parameters were estimated by using a Bayesian framework with the $\mathrm{MCMC}$ algorithm in the package GeoRglm in the R statistical software. MCMC methods involve the construction of a Markov chain (a mathematical representation of a random process where future values are conditionally independent of past values, and depend only on the present value), with the desired probability distribution at its equilibrium (the stationary posterior distribution which the chain will converge to following a suitable number of iterations). Samples can then be drawn from the equilibrium distribution and summarized to provide parameter estimates, Quintiles, and other measures of the distribution. Non-informative, uniform priors (in Bayesian inference a prior is a probability distribution expressing uncertainty about a parameter before taking into account data observations) were selected for each parameter to represent prior knowledge of their distributions. This allows the observed data to have the greatest influence on posterior distributions without being constrained by the choice of prior and can also improve MCMC convergence. The number of cases in each location is Poisson distribution and the natures of the data are counted, however, the variance of the parameters was overdispersed, as a result; Poisson regression was extended to the negative binomial regression model.

Colinearity among all possible pairs was done and if any couple has had a coefficient of correlation $>|0.7|$ indicated the presence of Colinearity. Variables that have Wald $\mathrm{P}>0.1$ were removed and $\mathrm{P}<0.05$ as the entry criterion for the stepwise Poisson regression. A scatter plot and classified predictor variables were used to examine non-linear interactions.

Using the Deviance Information Criterion (DIC), the quality of each model was evaluated (17). A Bayesian ' p-value ' analog was calculated from the predictive posterior distribution to evaluate the predictive capability of the models. In particular locations, we should calculate the area of the predictive posterior distribution which is more extreme than the observed data. The model predicts the observed data well for a specific location when the observed data are close to the median of the predictive posterior distribution and therefore the "p-value" close to 0.5 . A box plot is used to summarize the "p-values" calculated from the test locations under a particular model. The box plot displays the minimum, the 25th, 50th, 75th quartile as well as the maximum of the distribution of the $p$-values.

\section{Results}


During the research period, the general average annual cumulative incidence of malaria was 29.90 per 100 populations at risk with $95 \% \mathrm{Cl}(29.89,29.99)$. The research included eight districts and all districts reported events of malaria over the period of the research. In the study period, 112,282 malaria incidents were recorded. Plasmodium falciparum was the dominant species which accounts for $70.7 \%(95 \% \mathrm{Crl} ; 69.3,71.8)$ and Plasmodium vivax accounts $27.1 \%(95 \% \mathrm{Cl} ; 26.1,28.1)$ of the total case. The highest malaria cases (71.78\%) were seen in adults over 15 years, while the other $19.72 \%$ and $8.5 \%$ were in the age between 5 to 15 and under five years respectively.

The highest burden of malaria cases has been noted in the districts of Metema, Quara, and Chilga from July to October (Figure-2). An analysis of the spearman's correlation coefficient between malaria and monthly weather conditions (relative humidity, Rainfall, Sunshine hour, Maximum temperature, minimum temperature, and wind speed) was carried out (Table 2).

Table 2

The correlation coefficients' analysis of malaria and climatic variables' in northwest Ethiopia, 2016

\begin{tabular}{|c|c|c|c|c|c|c|c|c|c|}
\hline & & $\begin{array}{l}\text { Monthly } \\
\text { Relative } \\
\text { humidity }\end{array}$ & NDVI & $\begin{array}{l}\text { Monthly } \\
\text { Rainfall }\end{array}$ & $\begin{array}{l}\text { Length } \\
\text { of } \\
\text { Sunshine } \\
\text { hour }\end{array}$ & $\begin{array}{l}\text { Maximum } \\
\text { Temperature }\end{array}$ & $\begin{array}{l}\text { Minimum } \\
\text { Temperature }\end{array}$ & $\begin{array}{l}\text { Monthly } \\
\text { wind } \\
\text { speed }\end{array}$ & Altitude \\
\hline \multirow[t]{2}{*}{$\begin{array}{l}\text { number } \\
\text { of } \\
\text { malaria }\end{array}$} & $\begin{array}{l}\text { Pearson } \\
\text { Correlation } \\
\text { Coefficient }\end{array}$ & $0.409^{\star *}$ & -0.12 & 0.07 & -0.047 & $0.31^{\star *}$ & $0.34^{\star \star}$ & -0.19 & $-0.39^{\star \star}$ \\
\hline & P-value & 0.00 & 0.25 & 0.49 & 0.65 & 0.00 & 0.00 & 0.06 & 0.00 \\
\hline
\end{tabular}

**. Correlation is significant at the 0.01 level (2-tailed)

*. Correlation is significant at the 0.05 level (2-tailed)

Based on correlation analysis, the highest significant positive correlation was found between malaria incidence and monthly relative humidity $(r=0.41, p=0.00)$, maximum temperature $(r=0.31, p=0.01)$ as well as minimum temperature $(r=0.34, p=$ 0.01). However, the correlation between malaria incidence and monthly rainfall, length of sunshine hour and monthly wind speed were not statistically significant.

In the Bayesian generalized negative binomial regression analysis, relative humidity (IRR; 1.04 (95\% $\mathrm{BCl}, 1.01-1.05), \mathrm{NDVI}$ [IRR; 2.74(95\% BCl, 1.35-5.58)], altitude [IRR; 0.97(95\% BCl, 0.98-0.99], the average maximum temperature [IRR; $1.07(95 \% \mathrm{BCl}$ (1.05-1.09)] and average minimum temperature[IRR; $1.04(95 \% \mathrm{BCl}(1.02-1.07)]$ were the significant variables in this study (Table 3).

Table 3

Estimation of malaria and its risk factor by using Bayesian generalized negative binomial regression model in north Gondar zone, northwest Ethiopia 2016

\begin{tabular}{|c|c|c|c|}
\hline \multirow[t]{2}{*}{ Variables } & \multirow[t]{2}{*}{ IRR } & \multicolumn{2}{|c|}{ 95\% Bayesian Credible Interval } \\
\hline & & Lower & Upper \\
\hline Altitude(M) & $0.97 *$ & 0.95 & 0.99 \\
\hline Normalized Difference Vegetation Index(NDVI) & $2.74 * \star$ & 1.35 & 5.58 \\
\hline Mean Maximum Temperature $\left(C^{0}\right)$ & $1.07 * \star \star$ & 1.05 & 1.09 \\
\hline Mean Minimum Temperature $\left(C^{0}\right)$ & $1.04^{\star \star \star}$ & 1.02 & 1.06 \\
\hline Rainfall (MM) & $1.01^{\vee}$ & 0.99 & 1.00 \\
\hline Relative Humidity (g/m3) & $1.04^{*}$ & 1.01 & 1.05 \\
\hline
\end{tabular}

* P-value $<0.05$ ** P-value $<0.01$ *** P-value $<0.001$ 


\section{Discussion}

This study determined the annual average incidence of malaria and identified climatic variables that affect its occurrence in highland and lowland areas of northwest Ethiopia.

The average annual malaria incidence rate was 29.9 per 100 populations. This is greater than studies conducted(9.7\%) in the northwest Ethiopia(18), (4.3\%) in Amhara region(5), (6.8\%) in the southern nation and national states(4) and (10.4-13.5\%) in Gambella; (7.6-14.1\%) in Tigray, (0.9\%) in Oromiya and (5.4\%) in Southern Nations Nationalities People's Regions (19) and (4.5\%) in Ethiopia(13). However, it is smaller than the research carried out in the Tigray region in 2011 (43\%) and 2014 (33\%) (20). The higher incidence of malaria in the study area might be related to a long rainy season and temperature variability $(13$, 20). The majority, $69.8 \%$, of the malaria cases were due to plasmodium falciparum species. This is consistent with other studies from the southwest part of Ethiopia (19). The high burden of plasmodium falciparum and plasmodium vivax in the region was also documented in another study(13). The cause could be the temperature that favors their growth; temperatures more than $18 \mathrm{C}^{0}$ for $\mathrm{p}$. falciparum and more than $15 \mathrm{C}^{0}$ for $\mathrm{p}$. vivax is suitable for the growth of these two species. The temperature is higher than the minimum indicated in most parts of Ethiopia, particularly in Northwestern Ethiopia(18). Research in Tanzania also endorsed this idea(21).

The malaria victims that accounted for about $71.8 \%$ are adults over 15 years old. This is consistent with other researches(22, 23). However, another research has shown that malaria infection decreases in this age group(24). The high occurrence of malaria in adults could be attributed to the high mobility of people in this age group to malaria-risk areas for farming and other reasons.

In early April, the significant transmission time was noted and reaching its peak at the end of June and July. Between October and November, the second peak was noted. Other surveys have shown that there are two peak transmission periods in Ethiopia during the summer, but the incidents of the disease are variable(25). However, whatever the point of departure, everybody agreed that the first wet (summer rain) season was high in malaria transmission, with the wet season following the end(25).

Keeping the other variables constant in the model, the estimated incidence rate ratio of malaria was increased by 1.04 for a unit increment of relative humidity. It is supported by other studies conducted in Mali, Bangladesh, and Mozambique (26-28). Humidity between $55-80 \%$ is suitable for the completion of the Plasmodium falciparum and Plasmodium vivax malaria parasite life cycles (26). It seems that humidity plays an important role in the life cycle of the mosquito. In the presence of high humidity values, the parasite would complete the necessary life cycle to increase the transmission of the infection. When there is a unit increment of altitude, the rate of malaria incidence was reduced by 0.95 times. These findings are in agreement with other studies $(27,29-31)$.

The estimated risk of malaria incidence was increased by 1.07 times for a unit increment of average maximum temperature. This is in line with other studies (32-35). It might be the effect of temperature for the development of mosquitoes, their survival, and reproduction (36). A study in the highlands of eastern Africa disclosed that a rise of $1 \%$ in minimum temperatures over 1-2 months and a rise of $1 \%$ in peak temperatures over $2-5$ months led to a rise of $80 \%-95 \%$ in the proportion of outpatients diagnosis of Malaria (37). However, another study conducted in Bangladesh found that temperature and numbers of malaria cases have no significant relationship(38). The development of the mosquito larvas and Plasmodium parasites is accelerated at high temperatures. A higher number of mosquito generations and greater abundance occur with enhanced growth rates. As temperatures rise, the transmission of malaria increases up to a rarely exceeded limit of $37 C^{0}(24,25)$. Higher temperature also increases the feeding rate of adult female mosquitos, which can increase the likelihood that the malaria parasite may transmit to uninfected human hosts $(39,40)$. The sporogenic cycle of plasmodium growth, which occurs in the mosquito, is also shortened by the fact that the temperature rises to an ideal rate $(25,41)$. Furthermore, insect longevity is temperature-sensitive and there are limited temperatures above which mosquito mortality increases and minimum temperatures below which insects become inactive(39). 
The effect of rainfall on malaria incidence is somewhat controversial. In this study, rainfall had no significant relationship with malaria incidence. The finding is supported by other studies that studied across different countries $(30,42)$. But, many other studies have found a positive correlation. Studies in Angola, Mozambique, Mali, Zambia, Uganda, Botswana, and Thailand, for example, have found that greater precipitation values are linked to greater malaria incidence $(26,31,43-46)$. In contrast, other studies have shown that precipitations are an important contributor to malaria reduction in some regions of India and Seri Lankas (26, 47-51).

The incidence rate of malaria was 2.75 times higher when a unit scale increment of normalized difference vegetation index. Other studies have also found a strong link between natural vegetation and malaria transmission (52-55). NDVI can serve as a surrogate variable that represents available water or conditions that are consistent with a higher likelihood of standing or pooled water. As precipitation falls to the ground and is absorbed by plant life, plants increase their biomass and therefore reflect radiation in the near-infrared region of the electromagnetic spectrum over a larger area than in times of vegetation senescence. It is therefore reasonable that if the water is widespread in order to enhance vegetation, there is a higher probability that water for mosquito reproduction will be accessible. Thereby probability of being infected, along with malarial transmission, rises as the mosquito population rises.

\section{Conclusion}

The finding of this study indicated that a greater incidence of malaria was observed in the study area when compared to the national statistics. Commonly reported metrological parameters (altitude, maximum and minimum temperature, relative humidity, and the normalized difference of vegetation index) were identified as predictors for malaria incidence. However, in surprising way wind speed, sunshine hour, and rainfall were not statistically significant predictors.

In particular, despite national monitoring programs and the Ministry of Health's attempts to eliminate this disease in our nation, the research showed that malaria is still a severe public health problem and the assessment gives additional insight into the underlying variables that specifically characterize malaria hazards in high-risk regions. Further studies at the village and the individual level would be important using primary data, including all areas of Ethiopia and explaining the local disease clustering by consideration other risk variables, such as soil temperature, air pressure, and socioeconomic factors. The communities and local authorities should implement the environmental control program and actively participate in it through campaigns aimed at clearing the bush.

\section{Abbreviations}

ADDS, Africa Data Dissemination Service BCL, Bayesian Credible Interval; CDC, Communicable Disease Control; CSA, Central Statistical Agency; DEM, Digital Elevation Survey; DIC, Deviance Information Criterion; IRR, Incidence Rate Ratio; EWAMA, Ethiopia West Amhara Metrology Agency; FMOH, Federal Minister Of Health; GIS, Geographical Information System; GLM, Generalize Linear Model

GPS, Geographical Positioning System; GTP, Growth and Transformation Plan; LST, Land Surface Temperature; MCMC, Markov Chain Mantel Carlo; MODIS, Moderate Resolution Imaging Spectro-Radiometer; NDVI, Normalized Difference Vegetation Index; NOAAS, National Oceanic And Atmospheric System; RR, Relative Risk; USG, United States Geological Survey; WHO, World Health Organization

\section{Declarations}

\section{Acknowledgments}

We would like to thank the North Gondar zone health office and west Amhara meteorology agency for providing the data.

\section{Funding}




\section{Conflicts of interest/Competing interests}

No

\section{Ethics approval}

The study was approved by the Institutional Review Board of the University of Gondar. Support letters were obtained from North Gondar health offices for retrieving retrospective malaria data from records.

\section{Consent to participate}

The research was done based on record review without contacting patients. All the information was kept confidential and no individual identifiers were collected.permission was obtained from the North Gondar zone health management information department.

\section{Consent for publication}

Not applicable

\section{Availability of data and material}

The datasets generated during and/or analyzed during the current study are available from the corresponding author on reasonable request.

\section{Authors' contributions}

All the authors have actively participated during conception and design, acquisition of data, or analysis and interpretation of data. All authors read and approved the final version of the manuscript.

\section{References}

1. World Health Organization. World malaria report. ed WH Organization. 2016.

2. Hung LQ, et al.,. Control of malaria: a successful experience from Viet Nam. Bulletin of the World Health Organization,. 2002;80: p. 660-666.

3. TilayeT. Assessment of malaria prevalence and knowledge, attitude and practice (KAP) in relation to malaria prevention and control in Gondar town, northern Ethiopia 2005.

4. Deribew etal. Incidence, prevalence and mortality rates of malaria in Ethiopia from 1990 to 2015. Malaria Journal. 2017.

5. Public Health Emergency Management (PHEM). Amhara National Regional State Annual malaria Report. 2012.

6. ÉlodieAnneVajda. Assessing the Risk Factors Associated with Malaria in the Highlands of Ethiopia: What Do We Need to Know? Tropical Medicine \& International Health. 2017.

7. Federal Ministry of Health (FMOH). National Strategic Plan for Malaria Prevention, Control and Elimination in Ethiopia:2014-2020. 2014.

8. Gosoniu L, Vounatsou P, Sogoba N, Smith T. Bayesian modelling of geostatistical malaria risk data. Geospatial Health. 2006;1(1):127-39.

9. Cressie NA. Spatial prediction and kriging. Statistics for Spatial Data, Revised Edition. 1993:105-209.

10. Diggle PJ, Tawn J, Moyeed R. Model-based geostatistics. Journal of the Royal Statistical Society: Series C (Applied Statistics). 1998;47(3):299-350. 
11. Diggle PJ. Overview of statistical methods for disease mapping and its relationship to cluster detection. Spatial Epidemiology: Methods and Applications. 2000:87-103.

12. Gelfand AE, Smith AF. Sampling-based approaches to calculating marginal densities. Journal of the American statistical association. 1990;85(410):398-409.

13. PMI. Ethiopia malaria operational plan FY. http://wwwpmigov/docs/default-source/default-document-library/malariaoperational-plans/fy14/ethiopia_mop_fy14pdf?sfvrsn=14Accessed 2017.

14. Centeral statistica gency. Ethiopia demography and health report. 2014.

15. Herring JWaD. Normalized Difference Vegetation Index (NDVI). Moderate Resolution Imaging Spectro-radiometer 2000.

16. Mellander PE GS, Gardenas Al, Bewket W, Bishop K. Summer rains and dry seasons in the upper Blue Nile Basin: the predictability of half a century of past and future spatiotemporal patterns. PloS one. 2013.

17. Omumbo JH, SI Snow, RW Tatem, AJ Rogers, DJ. Modelling malaria risk in East Africa at high-spatial resolution. Tropical Medicine \& International Health. 2005;10(6):557-66.

18. Alemu Ke. Spatiotemporal clusters of malaria cases at village level, northwest Ethiopia. Malaria journal. 2014;13(1):223.

19. Adhanom T, etal In Epidemiology and ecology of health and disease in Ethiopia. . Ethiopia, Addis Ababa: Shama Books,. 2006.jpp: 556-576.

20. Teklay.H.etal. Pattern and Trend of Malaria Morbidity and Mortality in Tigray Region, Ethiopia from 2011/12-2014/15. Bioanalysis \& Biomedicine. 2017.

21. Smithson P. Down but not out. The impact of malaria control inTanzania Ifakara Health Institute, . 2009.

22. Mellander PE e. Summer rains and dry seasons in the upper Blue Nile Basin: the predictability of half a century of past and future spatiotemporal patterns. PloS one. 2013.

23. Dereje B.etal. Spatial Modelling of Malaria Prevalence and Its Risk Factors in Rural SNNPR, Ethiopia: Classical and Bayesian Approaches. American Journal of Theoretical and Applied Statistics. 2017;6(6):254.

24. MidekisaA.etal. Seasonal associations of climatic drivers and malaria in the highlands of Ethiopia. Parasites \& Vectors 2015;8:339

25. Beck-Johnson LM NW, Paaijmans KP, Read AF, Thomas MB, . The effect of temperature on Anopheles mosquito population dynamics and the potential for malaria transmission. Bjornstad ON PLoS One. 2013;8(11), e79276.

26. Andersson.M. ZOa. Spatial and temporal patterns of malaria incidence in Mozambique. Malar J. 2011;10: 189.

27. Haque.U e. The role of climate variability in the spread of malaria in Bangladeshi highlands. PLoS One. 2010;5: e14341.

28. Sogoba N. Spatial distribution of malaria transmission in relationship to" Anopheles gambiae" complex members in Sudan savanna and irrigated rice cultivation areas of Mali: University_of_Basel; 2007.

29. Hay SI e. Clinical epidemiology of malaria in the highlands of western Kenya. Emerg Infect Dis. 2002;8: 543-548.

30. Noor AM e. The risks of malaria infection in Kenya in 2009. BMC Infect Dis. 2009;9: 180.

31. Gosoniu L e. Bayesian geostatistical modeling of malaria indicator survey data in Angola. PLoS One. 2010 5: e9322.

32. Bhattacharya S e. climate change and malaria in India. Curr Sci. 2006;90: 369-374.

33. Gosoniu L, Vounatsou P, Sogoba N, Maire N, Smith T. Mapping malaria risk in West Africa using a Bayesian nonparametric non-stationary model. Computational Statistics \& Data Analysis. 2009;53(9):3358-71.

34. TianL e. Oneyear delayed effect of fog on malaria transmission: a time-series analysis in the rain forest area of Mengla County, south-west China. Malar J. 2008;7: 110.

35. Nkurunziza.H e. Bayesian modeling of the effect of climate on malaria in Burundi. Malar J. 2010;9: 114.

36. PatzJA HM, Rosenzweig C, Mitchell TD, Goldberg RA, Githeko AK, etal. Climate change-regional warming and malaria resurgence. Nature. 2002;420(6916):627-8.

37. ZhouG e. Climate variability and malaria epidemics in the highlands of East Africa. Trends Parasitology. 2005;21: 54-56. 
38. Noor AM CA, Gething PW, Moloney G, Borle M, Shewchuk T, Hay SI, Snow RW: . Spatial prediction of Plasmodium falciparum prevalence in Somalia. Malar J 2008;7:159. doi:10.1186/1475-2875-7-159.

39. Martens WJM NL, Rotmans J, Jetten TH, Mcmichael AJ. Potential impact of global climate-change on malaria risk. Environ Health Persp. 1995;103(5):458-64.

40. Beck-Johnson LMN, W.A.; Paaijmans, K.P.; Read, A.F.; Thomas, M.B.; Bjornstad, O.N. . The effect of temperature on Anopheles mosquito population dynamics and the potential for malaria transmission. PLoS ONE. 2013;8, 11. .

41. Beier JC.etal. Malaria parasite development in mosquitoes. Annu Rev Entomol. 1998;43:519-43.

42. Briet J. etal. Temporal correlation between malaria and rainfall in Sri Lanka. Malar J 2008;7: 77.

43. Kleinschmidt I, Omumbo J, Briet O, Van De Giesen N, Sogoba N, Mensah NK, et al. An empirical malaria distribution map for West Africa. Tropical Medicine \& International Health. 2001;6(10):779-86.

44. ZhouG MN, Githeko AK, Y. . Association between climate variability and malaria epidemics in the East African highlands. . GYProc Natl Acad Sci U S A. 2004;101(8):2375-80.

45. Riedel N, Vounatsou P, Miller JM, Gosoniu L, Chizema-Kawesha E, Mukonka V, et al. Geographical patterns and predictors of malaria risk in Zambia: Bayesian geostatistical modelling of the 2006 Zambia national malaria indicator survey (ZMIS). Malaria journal. 2010;9(1):37.

46. Thomson MC e. use of rainfall and sea surface temperature monitoring for malaria early warning in Botswana. J Trop Med Hyg 2005;73(1):214-21.

47. WiwanitkitV.etal. Correlation between rainfall and the prevalence of malaria in Thailand. MalarJ. 2006;52: 227-230.

48. Jombo GTA e. Malaria self medications and choices of drugs for its treatment among residents of a malaria endemic community in West Africa. Asian Pac J Trop Dis 2011;1(1): 10-16.

49. George Peter e. Study comparing the clinical profile of complicated cases of Plasmodium falciparum malaria among adults and children. Asian Pac J Trop Dis. 2011;1(1): 35-37.

50. Alaya N Ben e. Completeness of malaria notification in Tunisia assessed by capture recapture method. Asian Pac J Trop Dis. 2011;1(3): 187-191.

51. Desta M, Ayenew T, Sitotaw N, Tegegne N, Dires M, Getie M. Knowledge, practice and associated factors of infection prevention among healthcare workers in Debre Markos referral hospital, Northwest Ethiopia. BMC health services research. 2018;18(1):465.

52. Anyamba AaTCJ. Analysis of Sahelian vegetation dynamics using NOAA-AVHRR NDVI data from 1981-2003. , . Arid Environments. 2005;63:596-614.

53. Fabricante I, M. Oesterheld, J.M. Paruelo. Annual and seasonal variation of NDVI explained by current and previous precipitation across Northern Patagonia. Arid Environments. 2009;73: 745-753.

54. Sogoba N, Vounatsou P, Bagayoko M, Doumbia S, Dolo G, Gosoniu L, et al. The spatial distribution of Anopheles gambiae sensu stricto and An. arabiensis (Diptera: Culicidae) in Mali. Geospatial Health. 2007;1(2):213-22.

55. AbbasB e. Malaria risk in Nigeria: Bayesian geostatistical modelling of 2010 malaria indicator survey data. 2015.

\section{Figures}



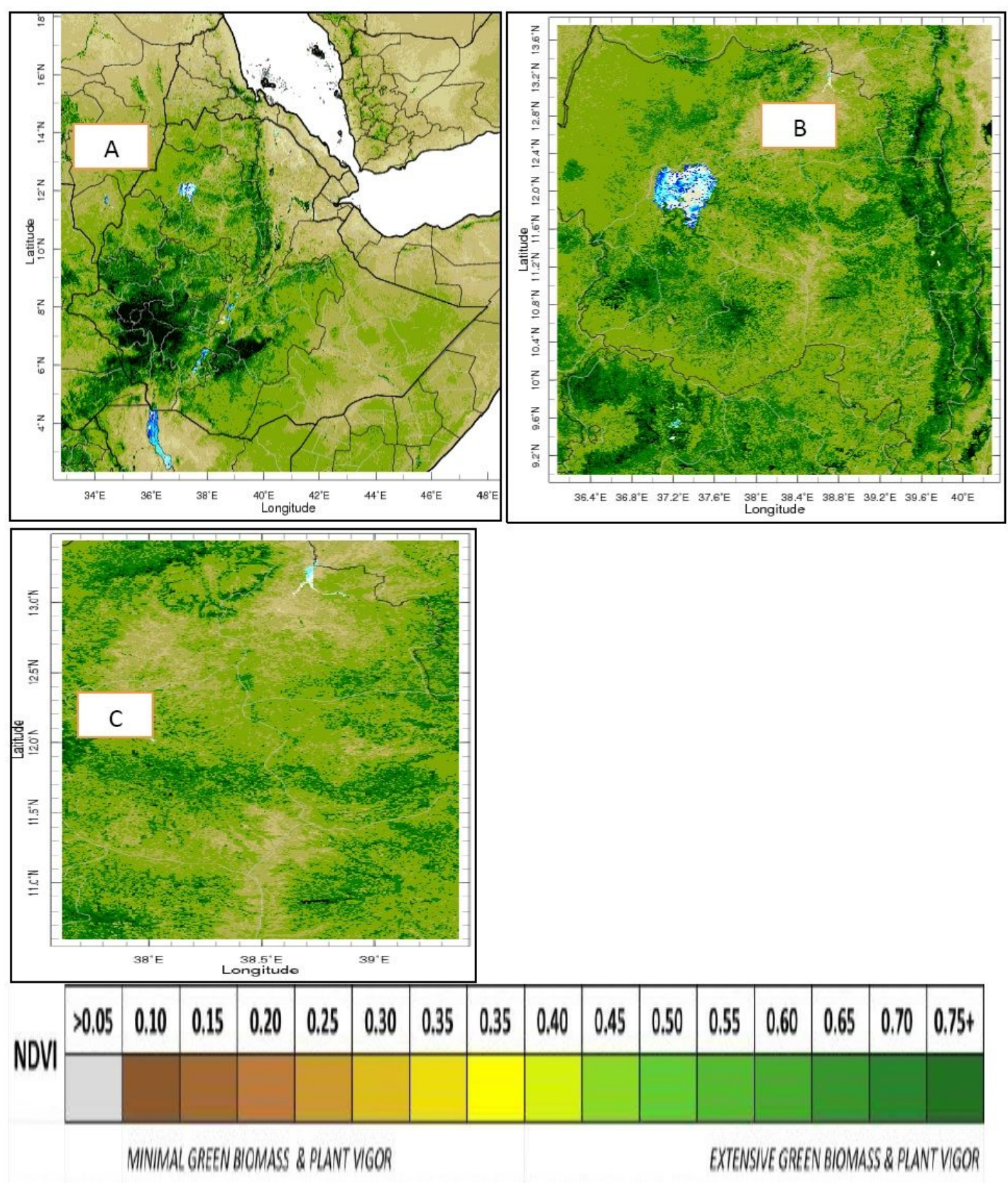

Figure 1

The NDVI maps of Ethiopia (A), Amhara regional state (B) and the study area, data extracted from Moderate Resolution Imaging Spectro-radiometer (MODIS) 2016. Note: The designations employed and the presentation of the material on this map do not imply the expression of any opinion whatsoever on the part of Research Square concerning the legal status of any country, territory, city or area or of its authorities, or concerning the delimitation of its frontiers or boundaries. This map has been provided by the authors. 


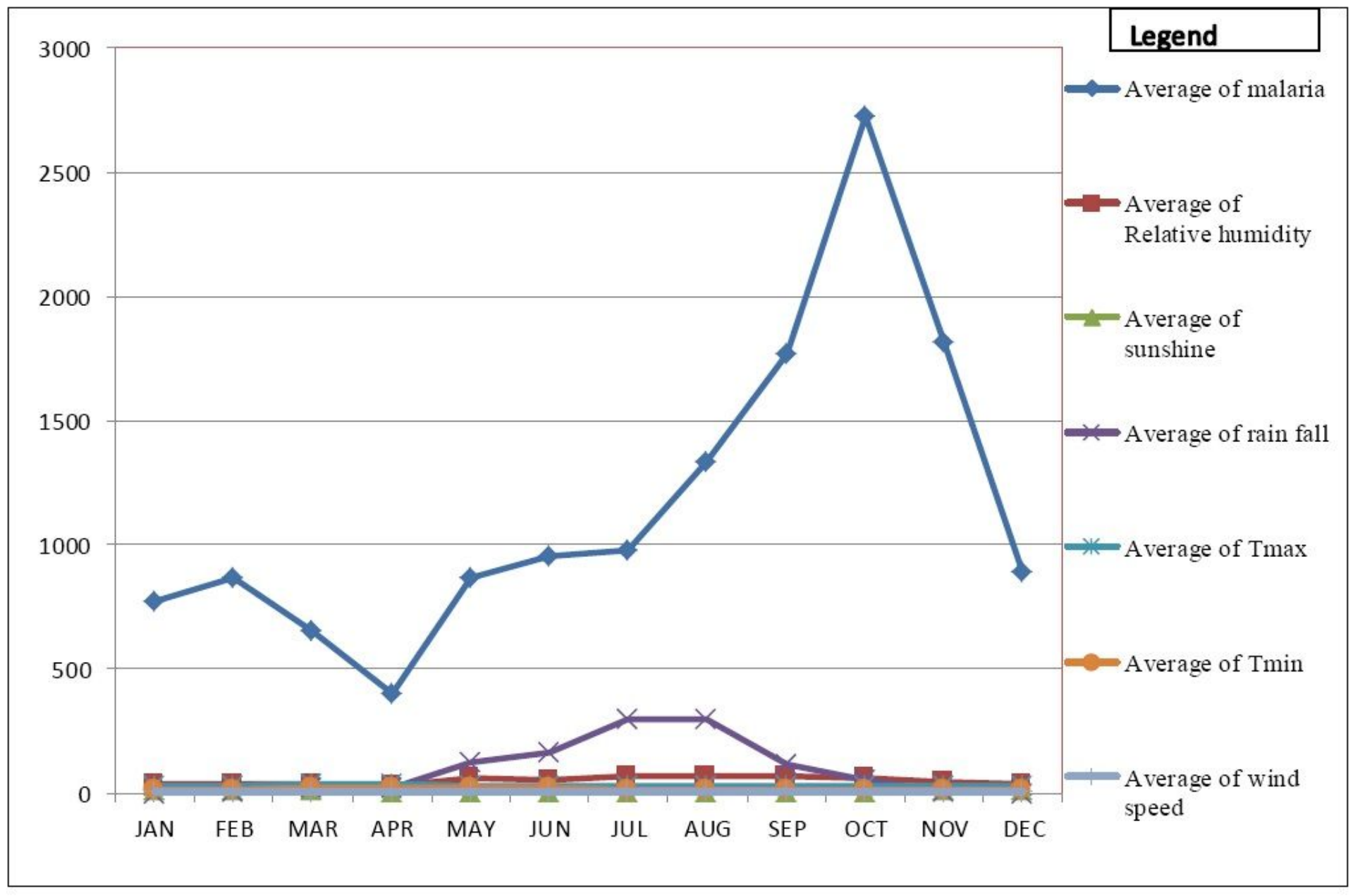

Figure 2

Average monthly recorded data of malaria and climatic variables' in North West Ethiopia 2016 